A somewhat similar type of amplifier is that which has been known since the days of Lord Rayleigh, and which has recently come into its own in the microwave field. This is the so-called parametric amplifier, and in essence it uses a time-dependent reactance to couple together two resonant systems, in such a way that energy is fed from the reactance variation to the resonant systems. The microwave engineering of this is quite complicated, as was evident from the slide shown, but such devices have been made to operate using either ferrites or garnets as the active material.

In the solids no electron beams are used in obtaining the amplification, and the only sources from which thermal fluctuations can arise are in the devices themselves, in their associated circuitry and from the driving oscillator. The masers have so far only been operated at liquid-helium temperatures (though it is possible that they may be usable at higher temperatures), and have extremely low noise. The parametric amplifiers will work at room temperature, which is a distinct advantage, but they are noisier than the masers, but comparable if not better than any other types of microwave amplifiers.
The immediate applications for which these amplifiers could be very valuable include their use in radio astronomy to detect the microwave radiations from outer space, in communicating with and observing Earth satellites and in increasing the sensitivity of radar systems.

The field of microwave physics which looked a few years ago to be a very specialized and limited one is in fact broadening out in much the same way that nuclear magnetic resonance has developed. Electron spin resonance apparatus is no longer to be found in a few university laboratories, for a number of industries and hospitals have realized its potential value, and there seems every likelihood that its value will be more widely appreciated in the next few years.

In view of this year's theme of the Association, it seemed appropriate to close Section A with an account of the way in which a rather specialized laboratory technique promises to become a powerful tool for industry, and it will be a very good example of the value of pure research to industry if the maser developments have their expected impact on the microwave industry.

\title{
TRENDS IN METALLURGY
}

GIR ANDREW McCANCE in opening, on September $S_{1}$, the session before Section B (Chemistry) of the British Association meeting in Glasgow, dealing with "Some Recent Trends in Metallurgy", reviewed in broad outline the progress made in the scientific world during the past few years and emphasized the important part that metallurgy had played in making this possible. He said the standard of living of industrial countries was indicated very largely by the steel consumption per head of population. By this standard the United States led the world with Germany and Britain 20 per cent and Japan 85 per cent below the American standard. British production per man employed had increased by 55 per cent since the War. This truly remarkable achievement had been brought about by an increase in the size of the producing unit, by improved equipment and by advances in technical knowledge such as the use of oxygen in steel-making.

The impact on metallurgical practice of the everincreasing demand for materials to withstand higher temperatures and pressures had been very marked and he felt that the difficulty of finding metals of such strength to withstand working temperatures of $800-900^{\circ} \mathrm{C}$. would cause a definite hold-up in progress. Though it was dangerous to argue from analogy, and we had only the most elementary guide to a pathway through the wilderness of ignorance, it was not out of place to point out that the most successful hightemperature alloy to-day was based on nickel with a melting point of $1,450^{\circ} \mathrm{C}$. and chromium with a melting point of $1,850^{\circ} \mathrm{C}$. The science of metals had lagged behind the technology of their use, and more imaginative work on factors contributing to their strength properties was a field offering great practical possibilities.

Creep and brittle fracture were two interesting problems of a fundamental nature, and though they had given rise to innumerable papers and much discussion yet remained in about the same state of advancement as they were ten years ago. In the case of brittleness it would appear that the results depended just as much on the type of test as on the nature and condition of the material being tested. A completely new approach to this problem would be welcome.

In the science of metals progress had resulted from the work of physicists rather than of metallurgists, and the fascinating developments in the use of semiconductors like germanium and silicon and the immediate applications to which inventions based on these discoveries had been put are outstanding achievements. However, during the past ten years much had been written about dislocations and they had been brought into the explanation of every conceivable property that metals possess. Sir Andrew regretted, however, that in many of these explanations there was more mathematics than physics and thought it doubtful if any real quantitative contribution had been made to our knowledge of the properties of metals by the dislocation theory, although it had contributed to our qualitative understanding of why metals behave as they do.

In a discussion of some recent applications of chemistry to metallurgy, Prof. R. Hay and Dr. P. T. Carter described the development of the modern highly mechanized iron blast furnace. Most of this development had resulted from the efforts of the engineer, but more recently, the metallurgist, using a chemical approach, had made important contributions. Investigations into the rate of reduction of different ores had led to the use of properly sized burdens, and petrological studies of the changes oceurring during sintering into lump form of the fines produced during crushing, or blown out of the top of the furnace, had shown that the formation of fayalite $\left(\mathrm{Fe}_{2} \mathrm{SiO}_{4}\right)$ caused a serious decrease in reducibility. Later work showed that fayalite formation could be avoided if the iron oxide particles could be bonded together by diffusion in the solid state, without melting occurring. 
When melting could not be prevented, fayalite forma. tion could be avoided by adding lime to form calcium silicate. In smelting lean ores, the incorporation of lime in the sinter mix ensured at the same time intimate mixing of the gangue and flux, and easy reducibility of the iron oxide, and now all the ore can be converted into easily reducible sinter, with a reduction of about 30 per cent in coke requirements.

Recent research into the constitution and properties of blast furnace slags was also described. A knowledge of their viscosities and melting points, and of their ability to control impurities in the iron such as sulphur and silicon, had contributed considerably to improved blast furnace practice in recent years.

The important effect of impurities on metal properties was described, and methods for their removal were discussed. Selective oxidation of impurities was well known, and recent compilations of thermodynamic data on metal/oxide systems allowed quantitative assessment of such methods. Selective chlorination could also be used, as in the removal of zinc from lead, and it was suggested that recent improvements in fluorine technology might result in similar applications for fluorine.

These methods introduce elements which may be as harmful as the original impurities. After selective oxidation, suitable deoxidizers-the choice being determined by cost, solubility and the formation of easily removable products-could be used, but the metal still contained small amounts of deoxidizing elements. The nearest approaches to the production of pure metal had been obtained by complicated and protracted chemical methods, or the comparatively simple zone-melting techniques developed by Pfann. Remarkable degrees of purification were possible, and in the case of germanium, impurities which affected its electrical properties could be reduced to less than one atom in $10^{10}$. Similar degrees of refining were possible with gallium and antimony, and most of the impurities could not be detected even by spectroscopic methods. Problems of contamination from the container used in the zone refining of reactive high melting point metals such as silicon, iron, germanium, etc., had been overcome by the use of floating zone techniques, in which no container was used, the molten metal being held in place by its own surface tension. Iron prepared thus showed ductility even at temperatures approaching $0^{\circ} \mathrm{K}$.

Gaseous impurities were more difficult to remove, but recently, induction vacuum melting and consumable electrode vacuum arc melting had been successfully applied to the production of large ingots. The former had been used particularly for the nimonic type of alloys, since it afforded close control of composition, and for certain special steels, and ingots up to $2,000 \mathrm{lb}$. had been made by this process. Consumable electrode processes in which air-melted electrodes were consumably remelted in water-cooled copper crucibles were now an integral step in the production of titanium, zirconium, molybdenum and many special alloy steels. They were less costly than vacuum induction melting, and could make ingots up to six tons.

Both processes were costly for the large tonnages usually encountered in steel-making, but vacuum degassing in the mould, which was cheaper and simpler, had resulted in considerable reduction in the hydrogen, nitrogen and oxygen contents of steel.

The newer metals in industry were discussed in a paper presented by Dr. H. M. Finniston and Dr. P. Murray. They pointed out that the newer metals fell into two groups. The first had a specific purpose for which it was difficult to see applications outside the field for which they were originally developed. To this group belonged uranium, thorium and pluton. ium, with perhaps germanium and silicon. The second group, which included titanium, zirconium, beryllium, niobium and molybdenum, was likely to have a wider field of application. For example, zirconium has very good corrosion resistance and niobium has potential. ities as a high-temperature creep-resistant material.

There were, however, several similarities between these metals. The extraction processes, because of the stability of their oxides, were all relatively complicated. All these metals were reactive and in many cases their physical properties, especially ductility, were adversely affected by small concentrations of gaseous impurities such as hydrogen, oxygen and nitrogen. This had led to developments in vacuum melting and casting techniques. In the case of the very high melting point metals thorium and niobium, powder metallurgy techniques had been employed with advancement in the use of high-pressure and high-temperature vacuum-sintering operations. The physical metallurgy of some of these metals was complicated due to the number of phase changes and to their alloying behaviour not conforming to the pattern of the more common metals.

In discussing the first group of metals the authors pointed out that the most interesting and important feature of uranium was its behaviour as a fuel in a reactor when bombarded with neutrons and this had introduced a completely new problem in metallurgical studies. At temperatures up to $350^{\circ} \mathrm{C}$, growth occurred due to change in crystal shape, and at temperatures higher than $350^{\circ} \mathrm{C}$. swelling of the metal took place. The former-generally referred to as 'wrinkling'-occurred in material with a marked texture and could be overcome by obtaining a randomly oriented fine-grained structure prior to irradiation. The latter effect was due to the nucleation of bubbles of the inert gases, krypton and xenon, produced by fission. This was accompanied by a marked decrease in density of the metal.

Plutonium, the synthetically produced metal from the uranium in the reactor, was metallurgically unique in that it existed in six different phases between room temperature and its melting point $\left(630^{\circ}\right.$ C.). Two of these phases exhibited negative coefficients of thermal expansion.

Of the second group of metals titanium was the most extensively used, largely as a structural material in alloy form in the aircraft industry. In the range $200-400^{\circ} \mathrm{C}$. titanium alloys possessed a better strength/weight ratio than either of its competitors, aluminium alloys and alloy steels. Above $400^{\circ} \mathrm{C}$. alloy steels were superior. Zirconium, although a high melting point metal, was also disappointing in that at medium temperatures its strength, like that of titanium, was not very good. All the early zirconium metal contained small quantities of hafnium, but although this metal is an identical twin of zirconium in chemical behaviour, in the nuclear reactor there is no such similarity. Though zirconium was virtually transparent to neutrons, hafnium absorbed so many that it is considered a most suitable material of construction for reactor control rods. Zirconium is primarily a sheathing material in pressurized water reactors where good corrosion resistance in water at temperatures up to $325^{\circ} \mathrm{C}$. is essential. Zirconium alloys have been developed with corrosion-rates as low as 1/5,000 in. per annum. 
Knowledge of beryllium and its properties has advanced considerably over the past ten years largoly as the result of its potential applications in nuclear reactors. It has been used for many years as an alloying element particularly with copper. The metal is extracted by two methods. The principal method is the thermal reduction process using magnesium reduction of beryllium fluoride at temperatures above the melting point of beryllium. The metal forms as globules which float to the surface of the bath. For removal of magnesium fluoride, melting in vacuo or under partial pressure of argon is employed. The other method of production uses the electrolysis of fused salts, mostly the eutectic mixture of sodium and beryllium chlorides, although fused fluorides have been used. Beryllium can be extruded over the temperature-range $400^{\circ}$ C. $-1,000^{\circ}$ C. Sheathing of the metal provides a solution to the health hazard, iron being the usual sheathing metal. A technique using the combined operations of powder metallurgy, consolidation and extrusion has been successfully developed. Beryllium is associated with inherent brittleness due to cleavage occurring along the basal plane. Attempts have been made to produce very pure beryllium. Zone refining has given disappointing results; but evaporation of vacuum-melted highpurity electrolytic flakes has yielded a very pure metal having an oxygen content of 10 parts per $10^{6}$. Such small crystals as were tested fractured in the normal fashion. Above $400^{\circ} \mathrm{C}$. the mode of failure changes from transcrystalline to intercrystalline; but the reasons for this change are unknown. In spite of such difficulties the metallurgist has succeeded in developing a wide variety of fabrication techniques and has also succeeded in joining beryllium to other metals and to itself.

Several methods have been proposed for the production of niobium such as electrolysis of fused potassium niobium oxyfluoride, the reduction of the oxide by the carbide and the reduction of potassium niobium fluoride by sodium or magnesium. The main method of consolidation is sintering of cold-pressed compacts. Niobium metal is an excellent 'getter' absorbing both oxygen and nitrogen rapidly on heating. Hydrogen is also absorbed at temperatures up to $500^{\circ} \mathrm{C}$. The elimination of non-metallic elements is essential for the production of ductile metal. The three main methods of purification which can be utilized during sintering are : (1) low-temperature eliminations of hydrogen up to $1,100^{\circ}$ C. ; (2) the formation of carbon monoxide above $1,650^{\circ} \mathrm{C}$.; (3) the elimination of oxygen probably by volatilization of an oxide of niobium at temperatures above $1,900^{\circ} \mathrm{C}$.
An important factor in attaining sound bars is the correct grading of the powder. Too fine powder sinters too quickly at the surface, resulting in retention of the gases and ultimate formation of gross internal voids. The sintered bar is cold forged and re-sintered at a maximum temperature of $2,300^{\circ} \mathrm{C}$. The resulting pure metal is ductile and can be formed cold by most of the usual methods. Hot forming is not possible owing to the pick-up of gases resulting in embrittlement. At present its only industrial use is in nuclear reactors as a canning material. If alloy development succeeds in realizing the potentialities of niobium as a high-temperature creep-resistant material and can overcome its poor oxidation resistance the field of possible application will be widened considerably.

In the final paper Dr. N. P. Inglis and Mr. J. B. Cotton discussed the corrosion behaviour of tantalum, niobium, titanium, zirconium and beryllium. All these elements readily form oxides, and this in part is a factor in their very resistant behaviour under a wide range of conditions. The oxide film can prevent further attack provided this film is very closely bonded to the metal. Investigations of the attack of various solutions ranging from hot fuming sulphuric acid through hot neutral salt solutions to hot strong sodium hydroxide solutions on these metals had shown that tantalum was the most resistant, being closely followed by niobium, while beryllium was attacked by all the corrosive media. Titanium had good resistance to neutral chlorides and it was estimated that titanium sheet of the thickness of a postage stamp would take four thousand years to disappear in sea water. Titanium, though not nearly so resistant to attack as tantalum, was much cheaper and showed fair resistance to non-oxidizing acids. This suggested further examination of the possibility of forming protective films to raise its resistance to that of tantalum, and it was shown that the growth of oxide films could be stimulated by slightly raising the oxide potential of the metal when in contact with the corroding medium. The method of raising the potential was not important, provided its value exceeded a certain critical value. Titanium could be protected by connecting it to a more noble metal such as platinum or carbon. This was shown with the aid of cine-film in which the behaviour of a piece of titanium without protection was compared with that of another piece to which a protective potential was applied. Another example of protection was shown in which titanium with an extremely thin surface-film of platinum and another piece without such protection were immersed in a current of sea water.

R. HAY

\title{
A NOVEL TYPE OF METAL-PROTEIN COMPOUNDS
}

\author{
By Prof. K. H. GUSTAVSON \\ Garverinäringens Forskningsinstitut, Stockholm
}

\begin{abstract}
AL proteins are capable of binding metal ions, A but the extent of binding and the stability of the metal-protein compounds vary greatly both with the nature of the metal ion, the nature of the protein and its net charge ${ }^{1}$. The transition group elements possess the greatest affinity for proteins generally and form the most stable compounds ${ }^{1}$. Positively charged polynuclear chromium complexes, such as
\end{abstract}

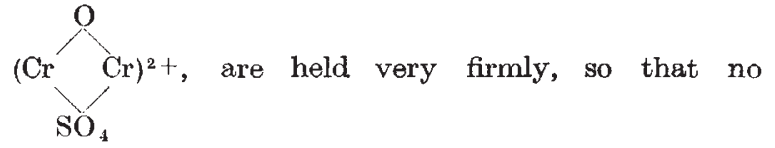

dissociation of the metal-protein complexes is detectable. The co-ordinate bond formed is largely covalent. The chromium complexes are potent 